\title{
Design Methods of Lightning Protection Systems by Keeping Aesthetic View of Architecturally Complex Structures
}

\author{
Mahesh Edirisinghe, Dammith Rupasinghe, C. Prasad Jinadasa \\ Department of Physics, University of Colombo, Colombo 03, Sri Lanka \\ E-mail address: mahesh@phys.cmb.ac.Ik
}

Keywords: Lightning; lightning protection; structural protection; suspension bridge protection

\begin{abstract}
The primary focus of this study is to understand design methods of appropriate lightning protection systems (LPS) for architecturally complex structures without any harmful affect to its aesthetic view. Two sites selected for this study consisting of architecturally complex structures named 'Kuruluduwa Suspension Foot Bridge' located in Matara, Sri Lanka $\left(6.05 \mathrm{~N}^{\circ} / 80.20 \mathrm{E}^{\circ}\right)$ and 'National Planetarium Building' located in Colombo, Sri Lanka $\left(6.95 \mathrm{~N}^{\circ} / 79.85 \mathrm{E}^{\circ}\right)$. Average lightning flash density for these two locations were $2.5 \mathrm{flyr}^{-1} \mathrm{~km}^{-2}$ and $2.3 \mathrm{flyr}^{-1} \mathrm{~km}^{-2}$ respectively. Different design methods were used to identify the most suitable LPS, based on the area of protection afforded by each one. After analyzing those two sites, it was able to introduce proper LPS for both sites by keeping architectural design as it is with no change for its aesthetic view. This study shows possibility of achieving this challenging task even for already constructed structures with present LPS standards successfully. When designing the architectural part of the structure, the architect should concern both on the visual appearance and the LPS. Creating a miniature model of the structure would be another suggestion which could be used to find the actual visual impact of the design and as well as to validate the protection system.
\end{abstract}

\section{INTRODUCTION}

Mankind come across several natural hazards like floods, avalanches, earthquakes, landslides, thunderstorms etc... that cannot be prevented. Only precautions can be taken against these events as risk reduction options which are known using technological \& scientific knowledge and their applications.

During the five year period of 2007-2011, National Fire Protection Association has estimated that the U.S. local fire departments are responsible for an estimated average of 22,600 fires started by lightning per year. These fires have caused for an estimated average of 09 civilian deaths, 53 civilian injuries and $\$ 451$ million in direct property damage per year [1]. The statistics show how hazardous a lightning could be and it must be prevented. The effects and consequences of a lightning compel the protection requirement against lightning. Thus the protection phenomenon becomes very important.

It is well known fact that when designing a lightning protection system (LPS) for a particular structure many factors should be considered such as geometry of the structure, type of construction, relative exposure, topography, lightning flash density at the location etc... However in addition to all of these factors which are regarding the protection, aesthetic view of some structures is also important as same as LPS. As a result of that the LPS are installing after the construction, most of LPS installers have been neglected about the view of the structure. Therefore some LPS systems completely or partially change the aesthetic view of the structures.

This study is mainly focused on finding the possible design methods or changing the existing system of LPS of architecturally complex structures without any harmful affect to its aesthetic view. The study was carried out as case studies considering two of the architecturally uncommon and historical structures in Sri Lanka. 


\section{METHODOLOGY AND DATA COLLECTION}

The study is primarily based on the two well known sites which are consisting of architecturally complex structures and with high historical value named 'Kuruluduwa Suspension Foot Bridge' located in Matara, Sri Lanka and 'National Planetarium Building' located in Colombo, Sri Lanka.

Data collected for various parameters from each two sites were almost same. Furthermore, structural details such as height, length, width, radius, materials, availability and functioning mechanism of LPS, grounding mechanism, architectural \& structural drawings, information on surrounding objects, damage history $\&$ lightning flash density at the locations also were collected. Damages and damage history to the structure from lightning were investigated by interviewing people who are working \& residing at each premises and suburbs. Detailed analyses were carried out to evaluate outlook changes to the architectural value of the structure with the available lightning protection system. Rolling sphere method and protective angle methods were considered to analyze the structures using full scale drawings for investigate proper LPS of both sites by keeping architectural design as it is with no change for its aesthetic view [2].

\section{LOCATION INTRODUCTION AND RATIONAL}

\subsection{Kuruluduwa Suspension Foot Bridge}

Figure 1 shows the Kuruluduwa suspension Foot Bridge which is built in 2007 and located near to the shore at the center of Matara town, Southern province in Sri Lanka. This bridge is the linkage between the Matara town and the Kuruluduwa Island and surround by the sea. There are no tall structures surrounded, which are taller than the bridge in the vicinity and exposed the structure to lightning. Therefore the bridge was strictly exposed to the lightning hazards for the pedestrians and also to structural equipments. There was no LPS installed to the bridge. The expected protecting volume was the deck, stay cables and the pylons of the bridge. The deck, pylon frame and stay cables are made out of galvanized steel. But hand rail top tubes, lower cables and pinnacles are made out of stainless steel. Normally structures like cable bridge deck, stay cables and steel pylons are strong enough to withstand a high lightning current by itself [3]. On the other hand as explained in [4], few lightning strikes were experienced in certain cable bridges in Japan and USA, particularly on the stay cables and even in some cases structure was collapsed.

\subsection{National Planetarium Building}

Figure 2 shows the National Planetarium which is located at Colombo 07, Western province in Sri Lanka and opened to public use in year 1965. The structure is conical shaped and spikes are mounted on the top of the roof and made out by concrete. The planetarium is located in the University of Colombo premises and not an isolated structure. The upper part of the structure was made by pre-cast concrete spikes which are some angle to the external side from the structure. If the spikes get damaged due to direct lightning strikes and falls, it could be very dangerous to the people at the ground level. The surrounding objects are tall buildings and some are even taller than the planetarium itself. The Franklin rod was in operation as the air termination to the building at the time of the investigation which is $1 \mathrm{~m}$ high and placed at the center of the structure. The protecting volume is the conical shape concrete structure and the concrete spikes on the top and bottom of the structure. Table 1 indicates relevant technical details of the two sites considered for this study. 


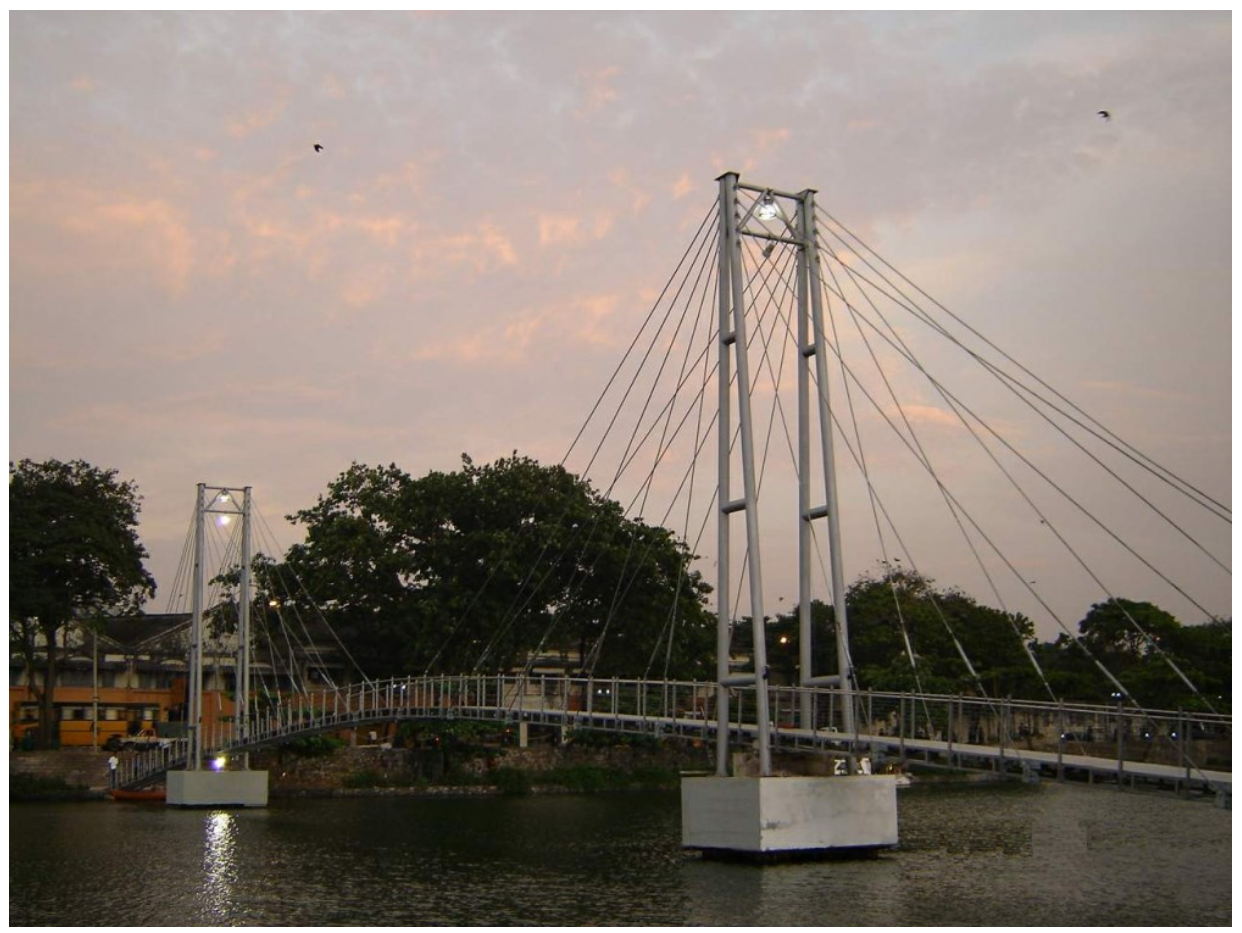

Figure 1. Kuruluduwa suspension Foot Bridge.

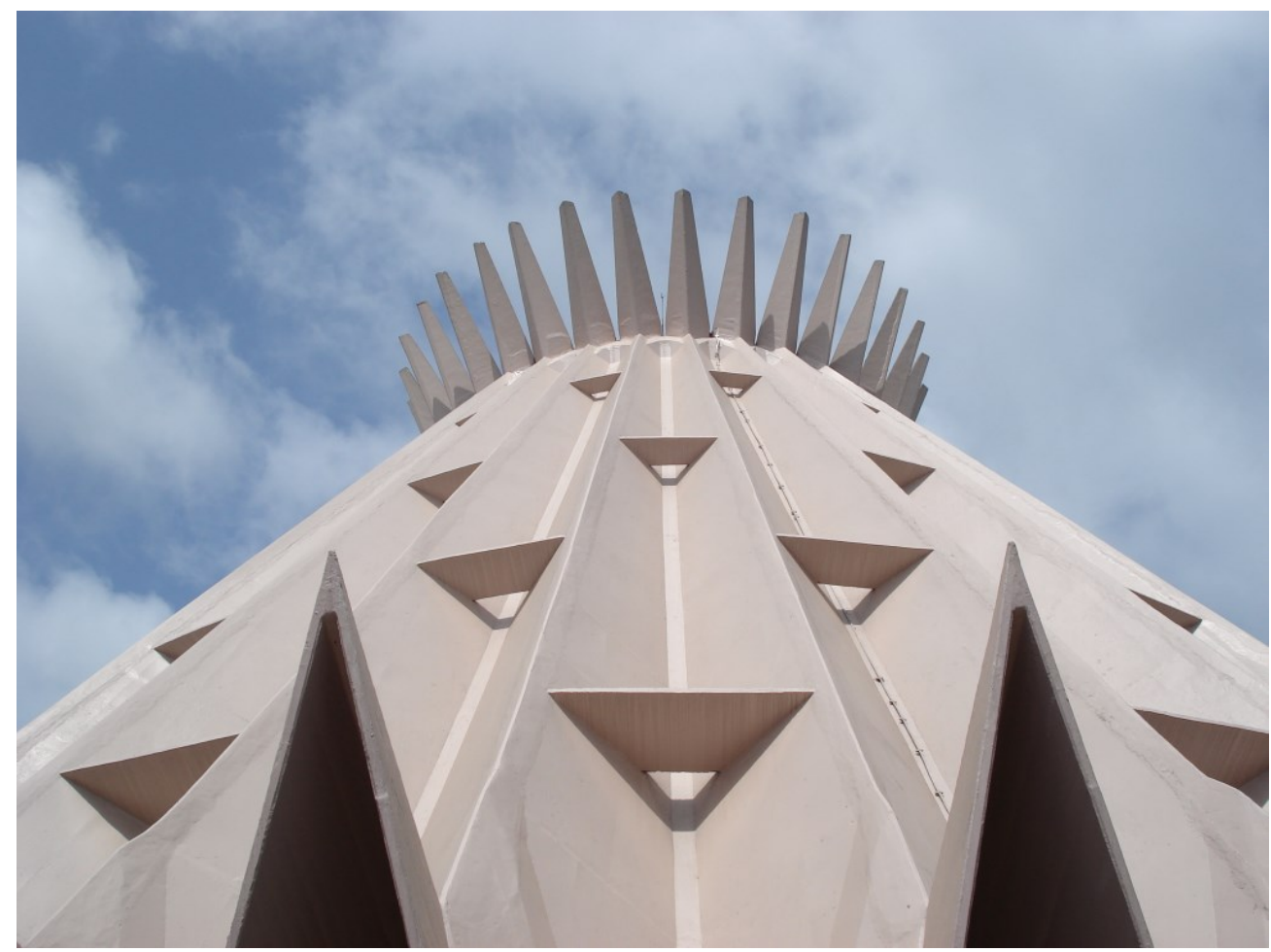

Figure 2. National Planetarium building. 
Table 1. Technical Details of Two Structures.

\begin{tabular}{|l|l|l|}
\hline \hline & Suspension Bridge & Planetarium Building \\
\hline Location coordinates & $6.05 \mathrm{~N}^{\mathrm{o}} / 80.20 \mathrm{E}^{\mathrm{o}}$ & $6.95 \mathrm{~N}^{\mathrm{o}} / 79.85 \mathrm{E}^{\mathrm{o}}$ \\
Length & $106 \mathrm{~m}$ & - \\
Width & $3.8 \mathrm{~m}$ & - \\
Height & $18.0 \mathrm{~m}$ & $25.5 \mathrm{~m}$ \\
Desk width & $1.8 \mathrm{~m}$ & - \\
Number of pylons & 2 & - \\
Pylon height & $16.0 \mathrm{~m}$ & - \\
Distance & $51.0 \mathrm{~m}$ (between pylons) & - \\
Supported cables & $48 \mathrm{cables}$ & - \\
Radius & - & $30.0 \mathrm{~m}$ \\
Type of materials & Mild \& stainless Steel & Concrete \\
Flash Density & $2.5 \mathrm{flyr}^{-1} \mathrm{~km}^{-2}[5]$ & $2.3 \mathrm{flyr}^{-1} \mathrm{~km}^{-2}[5]$ \\
Availability of LPS & Not available & Available \\
Damage History & No damages recorded & No damages recorded \\
\hline \hline
\end{tabular}

\section{PROPOSED MODIFICATIONS AND RECOMMENDATIONS}

The primarily concern of the research is to understand the nature of the lightning protection design methods for architecturally complex structures. Two selected sites were visited and analyzed as case studies and introduced some modifications further to propose lightning protection system for those structures by keeping its aesthetic view.

\subsection{Modification for Kuruluduwa Suspension Foot Bridge}

Potential lightning attachment points of the structure includes steel pylon, stay cables and the deck as shown in Figure 3(a). Out of all three points stay cables are the most at risk from a direct lighting strike where the importance of designing a LPS is required. Furthermore, the top level of each and every highest stay cables are the vulnerable points compared to other lower cables. The deck and the stay cables are partially protected by the pylons by itself. Further installing a Franklin rod on top of the pylons, only protects the pylons, some part of the deck and stay cables which are shown in Figure 3(b). However as in [3], the pylons are protected by Franklin Rods of Chalkida Cable Bridge in mainland of Hellas with the island of Evia but it was visually disturbing the architectural view of the bridge. On the other hand, the top of every pylon of Kuruluduwa Suspension Foot Bridge consist of stainless steel pinnacle and it can be used as a natural air terminal component without any change of its architectural view.

Down conductor can be connected through steel frame of pylon from the pinnacle to earth electrodes. The earth electrodes can be installed near the pile foundation of the pylons at the sea level. The electrodes made out of copper and the connections with the rest steel LPS conductors were through bimetallic elements to avoid electrochemical corrosion. The earth electrodes can installed in the sea water, which would give a very low earth resistance since the sea water, has very high conductivity. This was justified by the study reported in [6], as there were less surface discharges on sea water due to lightning flash, and penetrates directly towards the sea water provide an efficient grounding system for the LPS.

Stainless steel high strength strands can be used to build a stretch wire above top stay cables, connect to the pylon frame and the deck to protect stay cables. Upper end of the stretch wire side should be connected to the down conductor which is coming from the pinnacle and the other end should be connected to the deck and all the other joints should be grounded.

Stainless steel pipe was run along the deck and lower parts were made out by stainless steel cables. This stainless steel pipe acts as a ring conductor to protect side flashes. This conductor should be grounded at both ends through earth electrodes. 

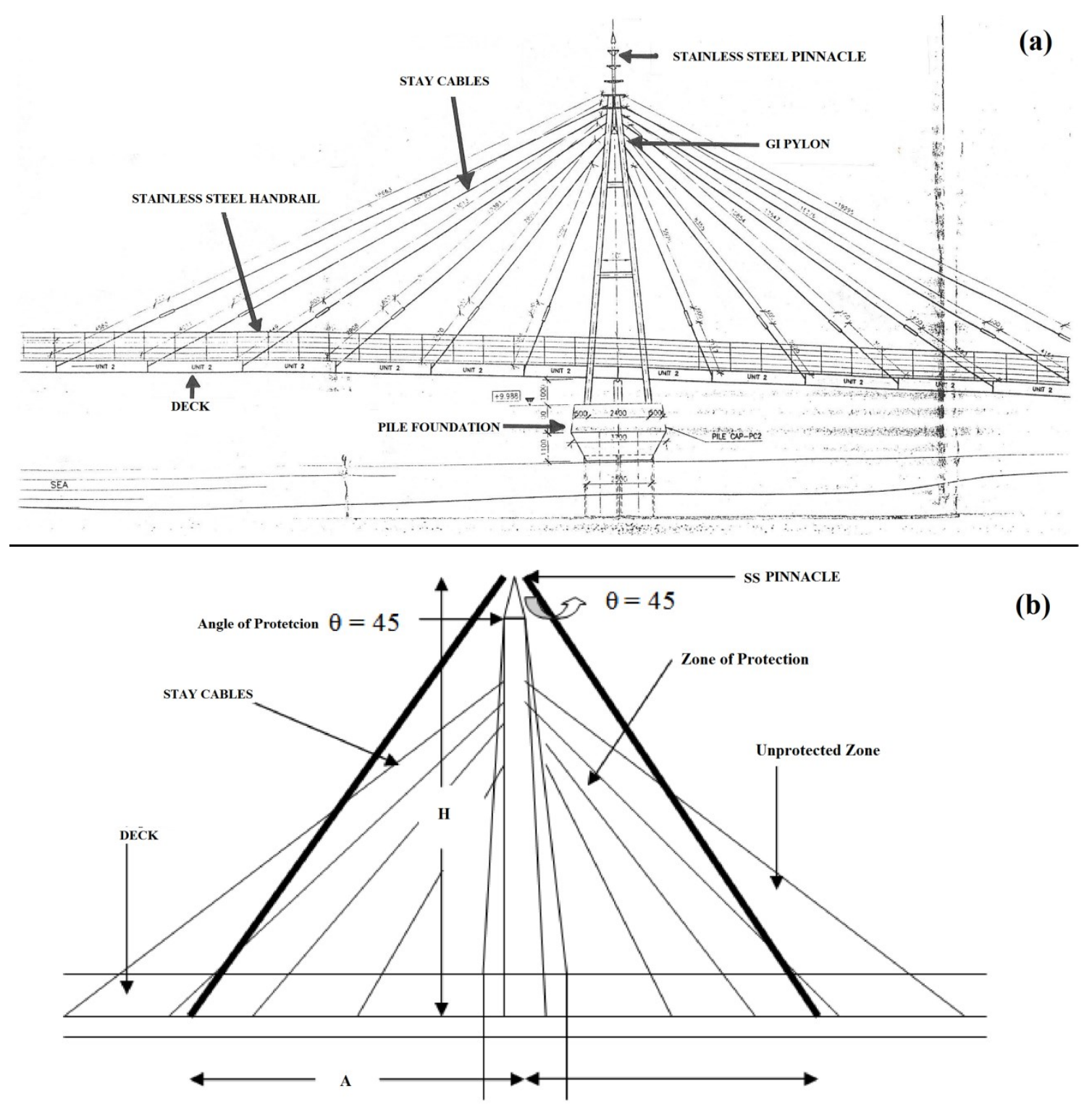

(b)

Figure 3. Kuruluduwa Suspension Foot Bridge (a) Structural drawing of the bridge (b) Application of protective angle method for the bridge.

\subsection{Modification for National Planetarium Building}

The Franklin rod which was installed on the top of the structure merely protects part of the building while adversely effecting to its esthetic view as indicated in Figure 4. Hence it was neither protecting the structure nor its architectural beauty. To find out a better solution, both rolling sphere method and the protective angle method were utilized. Initially, using the rolling sphere method identifies vulnerable points of the planetarium as shown in Figure 5. Concrete spikes at the top part of the structure are the main exposed points of the structure and air terminals can be placed on the top of each spike. As shown in Figure 6 using the protective angle method shows that placing these air terminals will protect the whole structure from potential lightning hazards. 


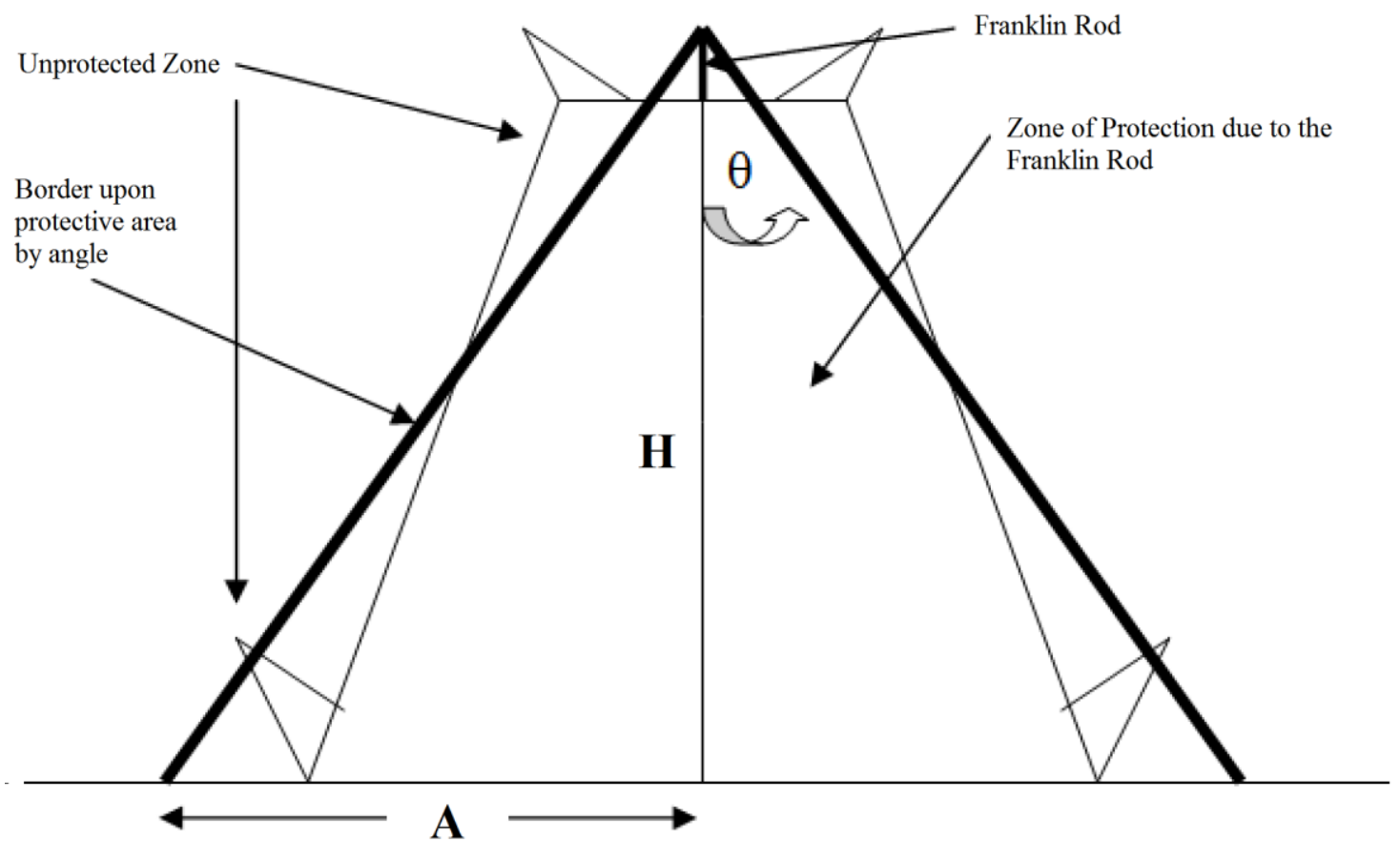

Figure 4. Application of protective angle method to the existing Franklin rod.

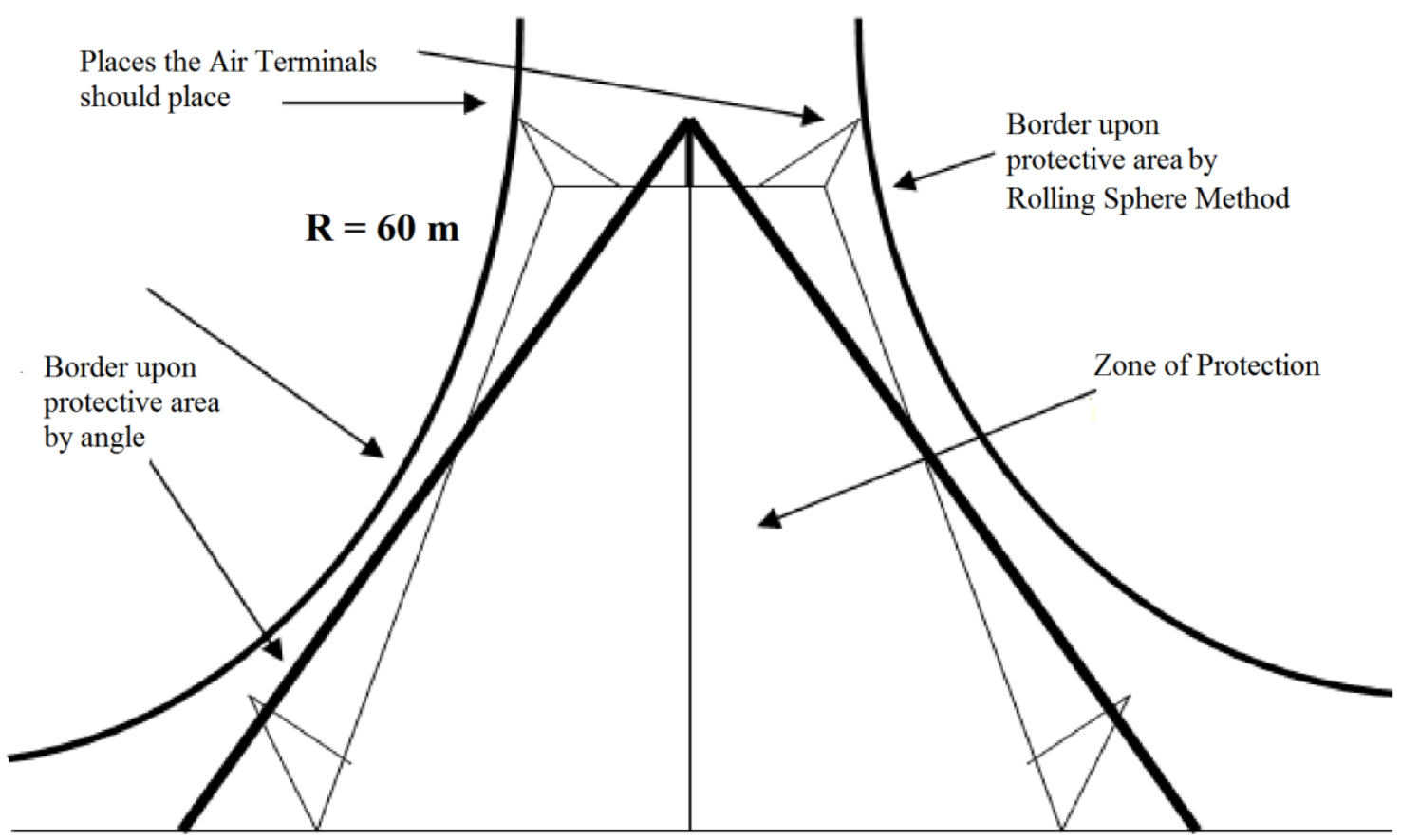

Figure 5. Application of rolling sphere method to indentify the vulnerable points.

Using air terminal such as Franklin rod on the top of each concrete spikes will adversely affect the scenic beauty of the planetarium. Hence instead of fixing a Franklin rod, a blunt metal cap proposed to be used in order to protect the structure as well as the architectural beauty of the building. Figure 7 shows the proposed air terminal system together with a copper ring conductor connecting each blunt terminal which is the best protecting solution for the building. 


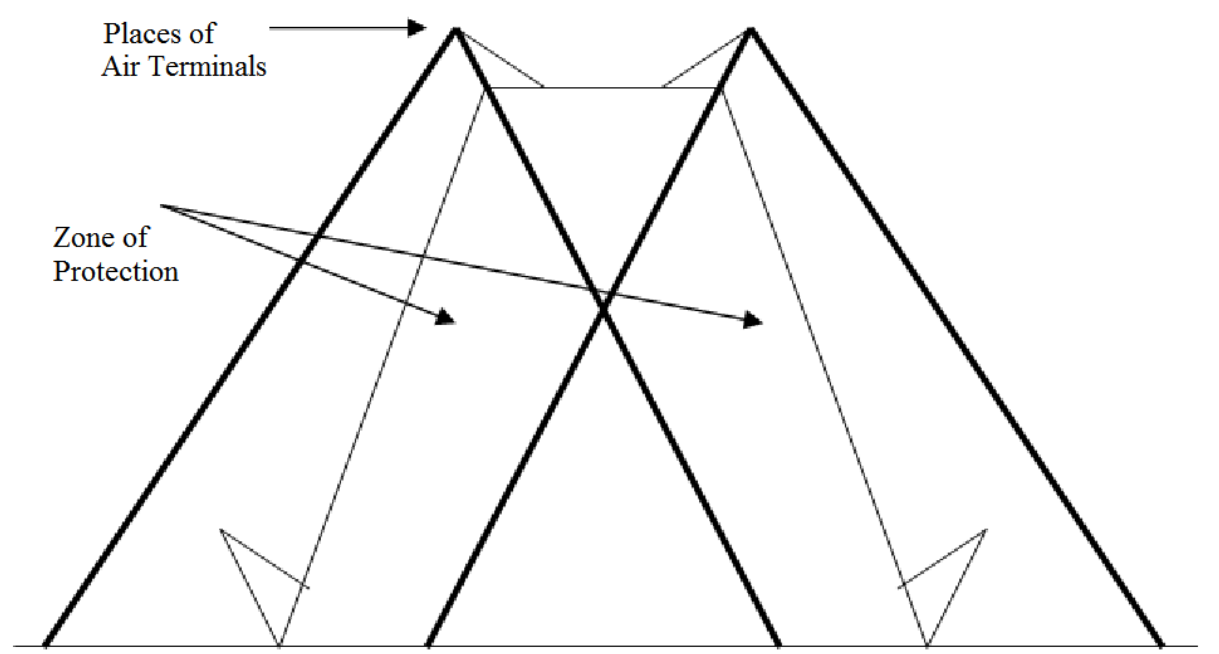

Figure 6. Placing of air terminal on top of the spikes of the planetarium building.

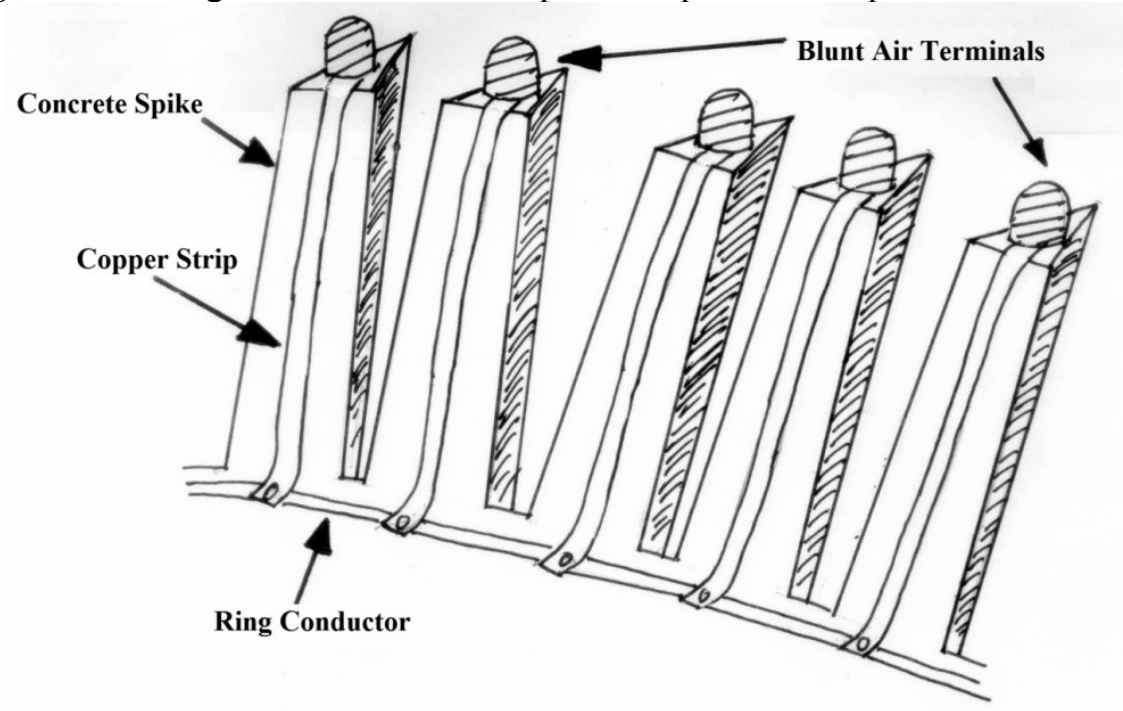

Figure 7. Proposed air terminal system planetarium building.

\section{DISCUSSION}

This study was mainly focused on to justify the possibility of design methods or changing the existence system of LPS for architecturally complex structures without any harmful affect to its aesthetic view. Rationalization of this study is significantly important because, aesthetic view of complex structures and ancient archeological sites are also important as same as LPS mentioned in $[4,5]$ which was mostly neglected in many countries at present. Furthermore as a result of that the LPS are installing after the construction, most of LPS installers have been neglected about the view of the structure. Therefore some LPS systems completely or partially change the aesthetic view of the structures in their perspective. Two case studies show that it is possible to introduce a proper LPS for the architecturally uncommon and historical structures in Sri Lanka without damaging the aesthetic view of the structure.

When designing the architectural part of the structure, architect concerns mostly on the visual appearance deeply, but not the lightning protection of the structure. However the lightning protection systems for complex structure should be designed at the planning stage of the building so that it can be introduced proper lightning protection system at the correct places of the building and avoid poor aesthetic view at the planning stage. This could reduce extra expenses of installation or replacements of new LPS when considering the value of the architectural design. Structural engineer and the architect should work together with lightning protection system engineer/consultant hence the structural components of the building (like reinforcements, Steel structural parts etc) can be used as a grounding components. 
Furthermore the designer of the LPS to an archeological site should be knowledgeable about the historical value of the structure and the surrounding. Thus the design and the installation of the LPS could be able to maintain and protect the both esthetic as well as the historical values of the site. Making a minimum model of the structure would be another recommendation which could be used in finding the actual visual impact of the design. Additionally theoretical techniques like rolling sphere methods can be used with more confidence and new hi-tech computer software could also be used instead.

The primary limitation of this study was the lack of researches and articles available regarding the concept between architecturally complex structures and lightning protection systems. Further it was evident that during the research there is limited number of cases found. Hence it is difficult to generalize the final conclusion according to the analyzed case studies. On the other hand, it is difficult to integrate whether the protection of structure from lightning is related to the LPS or not. It is also important to consider that some structures are protecting from the lightning by some surrounding objects. Furthermore up to date knowledge on the variation of lightning flash activity and other environmental conditions are also important in the case of analyzing the lightning risk level for the particular area of interest. However the purpose of the research is open doors to such extensive research.

\section{CONCLUSIONS}

This study shows the possibility of achieving a proper lightning protection system for architecturally complex structures without changing or damaging the aesthetic view of the structure even for already constructed structures and with present LPS standards successfully. When designing the architectural part of the structure, it is important that the architect should concern both on the visual appearance and the lightning protection system.

\section{References}

[1] Marty Ahrens, "Lightning Fires and Lightning Strikes," National Fire Protection Association, Fire Analysis and Research Division, pp. 1, June 2013.

[2] M. Becerra, V. Cooray, and F. Roman, "Lightning Striking Distances of Complex Structures", IET Generation, Transmission and Distribution, 2/1, 2008, pp 131-138.

[3] D. Kokkinos, et.al., "Lightning Protection of Cable Bridges", $28^{\text {th }}$, International Conference on Lightning Protection, ICLP 2006, pp 1364-1367.

[4] A. Ronsseau, L. Boutillon, and A. Huynh, "Lightning Protection of a Cable Stayed Bridge", $28^{\text {th }}$ International Conference on Lightning Protection, ICLP 2006, pp 1410-1413.

[5] V. Jeyanthiran, M. Edirisinghe, M. Fernando, and V. Cooray, "Study of lightning activity over Sri Lanka," $29^{\text {th }}$ International Conference on Lightning Protection - ICLP 2008, pp 2-10-1-2$10-10$.

[6] Mahesh Edirisinghe, Athalanka Liyanage, and Vernon Cooray, "Critical Electric Field Needed for the Propagation of Surface Discharges on Water," IEEE- $31^{\text {st }}$ International Conference on Lightning Protection, ICLP 2012, Austria. 